Acta Theriologica, Suppl. 3: 165-182, 1995.

PL ISSN 0001-7051

\title{
Breeding tactics, social structure and genetic variation in mammals: problems and prospects
}

\author{
Moira J. van STAADEN
}

\begin{abstract}
van Staaden M. J. 1995. Breeding tactics, social structure and genetic variation in mammals: problems and prospects. [In: Ecological genetics in mammals II. G. B. Hart] and J. Markowski, eds]. Acta Theriologica, Suppl. 3: 165-182.

Breeding tactics and social structure are among the primary determinants of the level and distribution of genetic variation in a population, giving rise to genetic structure. However the effects of such behaviors are neither intuitively obvious nor predictive. Interpretations of genetic interactions are hampered by a lack of suitable underlying models and the resulting weak empirical data base means that we are presently unable to answer fundamental questions such as whether the social structure exhibited by a species has any necessary or consistent relationship with the extent of genetic population structure in the species. In this review I present a brief overview of recent theoretical models, and summarise results of the two most common empirical approaches; namely, genetic comparison of identified social groups, and studies of arbitrarily selected samples. Some recommendations are made with respect to future empirical investigations. Increased sophistication in classifying social complexity will be necessary to elucidate the effects of social structure and breeding tactics on partitioning of genetic variation, and to determine the true correlation between social level and genetic structure.
\end{abstract}

Institute for Zoology, Karl-Franzens-University Graz, Universitätsplatz 2, A-8010 Graz, Austria; E-mail: m.van-staaden@kfunigraz.ac.at

Key words: genetic structure, social organization, behavior, breeding tactics

\section{Introduction}

Breeding tactics and social structure are among the most prominent behavioral factors which determine the genetic structure of a population. Variations in the size, sexual composition, and relatedness of social groups, as well as the choices involved in philopatry, timing of dispersal and mating, and number and degree of independence of mates, interact to influence the level and distribution of genetic variation in organismal populations. The objective of this article is to assess methods, to highlight some telling examples, and to identify future challenges in examining such interactions. Consideration of genetic variation is limited to nuclear variation, primarily allozymes. Alternative assays of genetic variation such as DNA fingerprinting, microsatellites and random amplified polymorphic DNA 
are applicable and would require only minor modifications of the methods discussed here (Lynch 1991, Lynch and Milligan 1994). In what follows, I will briefly outline the genetic expectations derived from mathematical models, describe results of several recent empirical studies, and make some recommendations for future studies in this area. The aim is not an exhaustive review of all studies dealing with the breeding tactics and social structure, but to emphasise the heuristic value of social models of population genetic structure and to demonstrate the value of combining population genetic and ethological study of genetic variation at the population level.

The propositions that behavior is the pacemaker of evolution (Mayr 1965), or that social structure is responsible for the rapid evolutionary rate of mammals (Wilson et al. 1975), are so intuitively appealing that they continue to be made even though significant supporting evidence is lacking. The causal determinacy between genes and phenotypic behavior is loose, and with the exception of the MHC system and its proposed effects on mating and cooperation, there is little evidence for major gene effects on normal behavior in mammals (Plomin 1990). While we do know that much of behavior is under polygenic control, it is not necessary to postulate direct genetic control of a behavior for it to be of evolutionary significance. Genes may be the correct currency by which to assess the evolutionary significance of a given process but they are not necessarily what causes evolution to take place; the link between behavior and genetics at the population level may be equally important. Behaviors which affect the level and distribution of genetic variation within and between subgroups of a population may play a substantial role in determining the evolutionary future of a population.

The impact of breeding tactics and social structure in mediating genetic differentiation among groups derives from the interactive effects of reduction in the genetically effective population size, inbreeding and gene flow among social units. Partitioning genetic variance into small units reduces effective population size, leads to rapid differentiation of subgroups and increases the allelic variance between groups. These factors are of practical importance in the conservation and genetic management of endangered species. Moreover, the potential for kin-correlated behavior is rooted in the basic processes that determine genetic population structure (Baker and Marler 1980). In theory, low levels of genetic variation within breeding groups and high levels between them should promote greater social interactions and cooperation within than between groups, thereby setting the stage for the evolution and maintenance of complex sociality.

There have been relatively few empirical studies exploring the degree to which social organization and breeding tactics can influence gene exchange within local populations (Selander 1970, Neel and Ward 1972, Schwartz and Armitage 1980, McCracken and Bradbury 1981, Bowen 1982, Chesser 1983, Singleton 1983, Pope 1992, van Staaden et al. 1994). Since the early studies on enclosed house mouse populations (Petras 1967, De Fries and McClearn 1972), most studies have ocused on the relationship between social and genetic structure (eg Daly 1981), emoloying 
a broad range of increasingly sophisticated statistical methods including spatial variance (Mantel 1967) and spatial correlation measures (Sokal and Oden 1991). Many have either failed to identify structure (Gaines and Krebs 1971, Waser and Elliott 1991) or concluded that it is of no evolutionary significance (McCracken and Bradbury 1977, Bowen 1982, Melnick et al. 1984). Several others have identified significant genetic structure between social groups of prairie dogs (Chesser 1983), ground squirrels (van Staaden et al. 1994), howler monkeys (Pope 1992), and humans (Neel and Ward 1972). However, our understanding of the influence of breeding and social strategies on genetic variation in mammalian populations remains far from complete.

\section{Theoretical studies}

The recent introduction of 'social' models (Chesser 1991a, b) has fundamentally changed the way in which population geneticists view social species. These differ from the classical models primarily in the distinction between social and demic population structures, and the explicit incorporation of behavioral parameters in the former. Whereas a deme is classically considered to be a panmictically breeding subunit relatively isolated from other such demes (Mayr 1965), a social unit comprises part of a single population of related individuals who are cohesive in breeding and dispersal behavior (Chesser 1991a).

To determine the role of female philopatry and male polygyny in partitioning the genetic variation within populations Chesser (1991a) modelled a common mammalian system where a small number of females per lineage are all bred by a polygynous male, such that all offspring within lineages are at least half-sibs, male offspring disperse and female offspring remain philopatric. Numerical solutions of coancestries for breeding scenarios with varying numbers of lineages, females and breeding males per lineage, indicated that with a finite number of lineages, individual inbreeding and inter-lineage coancestry accumulate continuously, decreasing the genetic variance within the population. Fixation indices were differentially affected but for all scenarios reached asymptotic values within approximately ten generations despite the steady loss of genetic variation within the population. This was also true when models were extended to include different breeding tactics and migration rates, indicating that the attainment of asymptotic fixation indices apply to any regular pattern of breeding and migration (Chesser 1991b). A similar conclusion can be derived from the simulation model of de Jong et al. (1994) based on the social system of Macaca fascicularis.

Theoretical studies demonstrate that social structure and breeding tactics have significant effects on the distribution of genetic variance (Chesser 1991a, b, Nunney 1993) and one cannot therefore simply extend traditional predictions of demic models to intrapopulational structures. One particularly noteworthy 
example of this is the existence of negative $F_{I S}$ values. Mathematical (Chesser 1991a) and simulation models (de Jong et al. 1994) indicate that for socially structured populations, genetic variance values within individuals relative to the social group are always negative, indicating excess heterozygosity within lineages. Such values are to be expected for any population in which breeding groups have been accurately identified, regardless of the number of male and female mates (Chesser 1991a). Within social populations, $F_{I S}$ is not a measure of individual inbreeding, and negative values are indicative of complicated substructure rather than inbreeding avoidance.

Substantial differentiation among social lineages and excess heterozygosity within lineages is expected even when males disperse randomly and indicates that lack of gene flow is not the only factor responsible for differentiation among breeding groups (Chesser 1991a). Mathematical models indicate that breeding tactics are much more important to the differentiation among lineages $\left(F_{L S}\right)$ than is migration rate (Chesser 1991b). Where migration rates are equal, a difference in the independence of mates impacts $F_{L S}$ and $F_{I S}$, but $F_{I L}$ is relatively unaffected. Thus, $F_{I L}$ is a robust indicator of breeding tactics. Similarly, when age structure is included in a model based on the Macaca fascicularis social system, de Jong et al. (1994) contend that $F_{I S}$, and $F_{S T}$ characterize the demography and life history of a population. The disproportionate influence of breeding tactics rather than migration on the ultimate $F_{L S}$ value indicates that Wright's (1951) island model is not applicable to models of intrapopulational differentiation (Chesser 1991b). Moreover, the degree of genetic differentiation among breeding groups, inbreeding coefficients, and gene correlations within lineages are primarily functions of breeding tactics within groups rather than gene flow among groups, and the evolution of polygynous breeding tactics is more favorable for promoting intragroup gene correlations than modifications of migration rates. So in fact evolution may favor development of different breeding tactics rather than limited migration for enhancing intragroup gene correlations (Chesser 1991b).

The effects of female philopatry are complex and somewhat counterintuitive. Female philopatry increases coancestry of offspring in the lineage over that for random female movement. However, a less predictable outcome is that for a given breeding tactic, female philopatry may be much more effective for increasing gene correlations among adults than among progeny. This is clearly not true in the case shown in Table 1, and emphasises the need to take cognizance of the relative values of group advantage accrueing in different breeding tactics (Chesser et al. 1993) and perhaps at different stages of the life cycle. According to Chesser (1991a) the fact that asymptotic fixation indices are reached more rapidly with polygyny than inbreeding scenarios, indicates that philopatry and polygyny probably evolved in concert in order to promote greater coancestry among lineage members.

Although breeding tactics are more important to genetic differentiation among social groups than are migration rates, Nunney (1993) demonstrated that the effect of extreme mating systems on effective population size $(\mathrm{Ne})$ is not as great as 
Table 1. Genetic variance partitioning for Richardson's ground squirrels from four matrilines in a single population. Analyses were conducted for all individuals $(n=66)$; separately for mothers $(n=24)$ and recruited female offspring of the 1985 cohort $(n=42)$; as well as combined $(n=76)$ and separately for pregnant females $(n=22)$ and embryos $(n$ $=54$ ) of the 1986 cohort. Analysis was based on five loci for the first three groups and a single one for the latter. Significance of the $F_{S T}$ values was determined by $\chi^{2}$-test and is indicated by asterisks (*** $p<0.001$ ).

\begin{tabular}{lrrrr}
\hline Group & \multicolumn{1}{c}{$F_{I T}$} & $F_{I S}$ & \multicolumn{1}{c}{$F_{S T}$} & \multicolumn{1}{c}{$\chi^{2}$} \\
\hline 1985 & & & & \\
$\quad$ Mothers & -0.390 & -0.456 & 0.046 & $608.3^{* * * *}$ \\
Recruits & -0.377 & -0.409 & 0.024 & $1112.9^{* * * *}$ \\
Combined & -0.366 & -0.397 & 0.024 & $1531.1^{* * * *}$ \\
1986 & & & & \\
Pregnant females & -0.013 & -0.030 & 0.017 & $428.3^{* * * *}$ \\
Embryos & 0.032 & -0.045 & 0.073 & $1861.9^{* * *}$ \\
Combined & 0.012 & -0.065 & 0.072 & $1840.4^{\text {**** }}$ \\
\hline
\end{tabular}

previously assumed. In comparing random union of gametes, monogamy, and three kinds of polygyny, he found that the ratio of $\mathrm{Ne} / \mathrm{N}$ (where $\mathrm{N}$ is the number of adults) is usually close to 0.5 , regardless of the mating system, and concludes that special circumstances are required both for $\mathrm{Ne}$ to be close to $\mathrm{N}$ and for $\mathrm{Ne} / \mathrm{N}$ to be much less than 0.5 . Ne depends strongly on both mating system and generation time. These factors interact such that $N e$ is close to N/2 in both simple (lottery polygyny) and highly polygynous (harem or dominance polygyny) mating systems. Where all males compete equally for females, $\mathrm{Ne}$ is lower than for either of the highly polygynous systems. Harem or dominance systems give very low values of $\mathrm{Ne} / \mathrm{N}$ when generation time $(T)$ is short, but as $T$ is lengthened, $\mathrm{Ne}$ approaches $N / 2$. The influence of a biased sex ratio, resulting from differences in either survival or recruitment of adults, depends on the mating system and, in general, is asymmetrical.

Overall, models clearly demonstrate that these contrasting population structures have differential effects on processes and patterns of genetic substructure; for example, genetic drift will cause genetic variance to be rearranged among constituent components of demes, but lost among social groups (Chesser 1991a). A major advantage of these models is the generation of testable hypotheses. Chesser et al. (1993) predict that social groups which are characterized by strong gene correlations are likely to exhibit relatively low group advantage for progeny survival and breeding. In contrast, there is little impetus for high gene correlations to accrue in situations where group advantage is very high relative to monogamous systems. In testing such hypotheses however, inference of migration and breeding tactics from empirical data of natural populations may prove difficult unless sampling regimes are meticulously designed (Chesser 1991b). 


\section{Empirical studies}

Recent investigations of breeding tactics and social structure fall into five distinct categories. The first approach assumes that population structure has certain genetic consequences and that by examining the genetics of arbitrarily selected individuals one can infer the population structure and deduce the effects of alternative behaviors (eg White and Svendsen 1992). A second approach entails comparison of the genetics of known social units, is applicable to well-studied species with sufficient natural history information to enable correct identification of social/breeding units, and may involve the analysis of pedigrees from long-term study of populations where members are individually marked (Pope 1992, van Staaden et al. 1994). Further approaches include the use of effective population size as a synoptic measure of social structure (Chepko-Sade and Shields 1987), the determination of genetic reponses to inbreeding and outbreeding (Templeton 1987) and surveys of heterozygosity level (Apollonio and Hartl 1993). Below I review recent studies, mostly of primates and rodents, utilizing the first two most common approaches.

Studies of arbitrarily selected samples

In the study of genetic structure, the dominant trend in recent years has been towards arbitrary sampling combined with spatial autocorrelation techniques. Waser and Elliott (1991) used spatial autocorrelation of allele frequencies at four loci in a single population of the bannertailed kangaroo rat Dipodomys spectabilis to test the hypothesis that restricted dispersal can lead to local genetic structure in small mammals. They detected significant deviations from expectations at seven of 78 Moran's $I$ values. Since these showed "no particular distribution" along the correlogram and no correspondence to results predicted from simulations, they conclude that there is no clustering of alleles, that the effective population size $(<15)$ is large enough to prevent local genetic structure, and that philopatry per se will not lead to local population differentiation in mammals.

White and Svedsen (1992) used spatial autocorrelation of alleles at five loci analysed as composite genotypes in two populations of the eastern chipmunk Tamias striatus to estimate the size of the genetic neighborhood and to try and identify the limits of dispersal and gene flow. Significant negative autocorrelation was noted at 120 and $240 \mathrm{~m}$ and is thought to indicate social interactions within the Ohio population deterring short distance dispersal. Estimates of genetic neighborhood size in the Michigan population indicate that mates are drawn randomly from a radius of $900 \mathrm{~m}$ around the focal animal. They conclude that significant spatial patterning exists in the larger Michigan population but not the Ohio population, and attribute this difference to the fact that the Ohio study area was only $1000 \mathrm{~m}$ across (5.2 ha). The validity of this comparison is somewhat reduced by large differences in the sampling regime and shape of the study areas. 
Moreover, van Staaden et al. (1994) detected significant genetic structure in a population of Richardson's ground squirrels Spermophilus richardsonii, in an area only $400 \mathrm{~m}$ across, where $96 \%$ of 148 adult females were sampled. In a larger sample of anonymous individuals from the same population, significant spatial autocorrelation of genotypes was found for females but not males, at five of six polymorphic loci examined. with the remaining locus showing evidence of selection (M. J. van Staaden et al., submitted).

Patton and Feder (1981) compared genetic variance partitioning in six non-contiguous areas containing the pocket gopher Thomomys bottae. Unidentified social structure within subpopulations gave rise to high positive mean $F_{I S}$ for subpopulations, due to pooling of samples that differ in allele frequency. 'Demic' structure within fields was as strong as that evidenced between fields. Where individuals could be assigned to groups within two fields, the $F_{S T}$ averaged 0.0697 and 0.0448 in different years. No evidence of multiple paternity was found and in contrast to behavioral observations which indicated that pocket gophers are promiscuous, the reproductive contribution of males was decidedly uneven in any given breeding cluster. This high variance in male reproductive success coupled with an adult sex ratio significantly skewed in favor of females, leads to very small effective population size ranging from 12 to 26 .

Daly (1981) examined the effects of social organization on determining the genetic structure of a population of wild rabbit Oryctolagus cuniculus. She examined variation in gene frequencies at three loci over 25 social groups (warrens). Comparing the observed frequency of offspring genotypes with the expected frequency of matings for a single locus under panmixia and for a subdivided population breeding entirely within groups, she concluded that the panmixia model best fit the data, that social organization does not lead to genetic micro-differentiation in rabbits and hence social structuring in mammals does not have major genetic consequences.

\section{Studies of identified social groups}

In almost all cases where known social groups were compared, significant genetic differentiation has been found. Table 2 summarizes variance partitioning results for several such studies. One of the earliest sources of evidence arguing for a high degree of micro-differentiation between social groups was the study of Neel and Ward (1972), comparing the genetic structure between villages in three South American tribes. Using Wright's $F$-statistics, they found genetic differentiation between villages to be $4-6 \%$, and documented negative $F_{I S}$ as a real effect, for which they clearly ruled out avoidance of close inbreeding as a possible cause.

Pope (1992) examined the relationship between social structure and partitioning of genetic variance in the red howler monkey Alouatta seniculus. She found significant differentiation among troops within populations in both a numerically stable and a rapidly growing population (Table 2). Despite high levels of observed 
Table 2. Measurements of genetic differentiation within and among identified social units of mammalian populations. Because known social groups are compared, we adopt the terminology of Chesser (1991a), in which $F_{I S}$ is biologically equivalent to that of Wright (1943), but genetic variance within subpopulations is further partitioned into that within and between social lineages. Calculatior of $F_{L S}$, $F_{I L}$ and $F_{I S}$ (Chesser 1991a) are mathematically equivalent to $F_{S T}, F_{I S}$ and $F_{I T}$ (Wright 1943), respectively. ${ }^{1}$ within wards of a single population, ${ }^{2}$ among wards of the same population, ${ }^{3}$ numerically stable population, ${ }^{4}$ rapidly expanding population.

\begin{tabular}{|c|c|c|c|c|c|}
\hline \multirow{2}{*}{ Species } & \multirow{2}{*}{ Social unit } & \multirow{2}{*}{$\begin{array}{l}\text { Number } \\
\text { of loci }\end{array}$} & \multicolumn{2}{|c|}{ Genetic variation } & \multirow{2}{*}{ Reference } \\
\hline & & & $F_{L S}$ & $F_{I L}$ & \\
\hline Thomomys bottae & clusters in a field & 11 & 0.057 & - & Patton and Feder 1981 \\
\hline Cynomys ludovicianus & $\begin{array}{l}5 \text { coteries }^{1} \\
5 \text { coteries }^{1} \\
8 \text { coteries }^{1} \\
4 \text { wards }^{2}\end{array}$ & $\begin{array}{l}7 \\
7 \\
7 \\
7\end{array}$ & $\begin{array}{l}0.152 \\
0.183 \\
0.216 \\
0.054\end{array}$ & $\begin{array}{l}0.002 \\
0.160 \\
0.142 \\
0.225\end{array}$ & Chesser 1983 \\
\hline Spermophilus richardsonii & 9 matrilines & 6 & 0.045 & -0.397 & van Staaden et al. 1994 \\
\hline Phyllostomus hastatus & 9 harems & 3 & 0.031 & - & $\begin{array}{l}\text { McCracken and } \\
\text { Bradbury } 1981\end{array}$ \\
\hline Desmodus rotundus & 6 harems & 7 & 0.075 & - & Wilkinson 1935 \\
\hline Saccopteryx bilineata & $\begin{array}{l}4 \text { female groups } \\
4 \text { male groups }\end{array}$ & $\begin{array}{l}3 \\
3\end{array}$ & $\begin{array}{l}0.013 \\
0.104\end{array}$ & - & McCracken 1987 \\
\hline Alouatta seniculus & $\begin{array}{l}14 \text { troops }^{3} \\
4 \text { troops }^{4}\end{array}$ & $\begin{array}{l}9 \\
8\end{array}$ & $\begin{array}{l}0.225 \\
0.142\end{array}$ & $\begin{array}{l}-0.161 \\
-0.064\end{array}$ & Pope 1992 \\
\hline Macaca mulatta & 5 troops & 5 & 0.040 & -0.085 & Melnick et al 1984 \\
\hline Macaca fascicularis & 7 social groups & 10 & 0.045 & 0.016 & $\begin{array}{l}\text { Scheffran and } \\
\text { de Ruiter } 1994\end{array}$ \\
\hline Cercopithecus aethiops & $\begin{array}{l}20 \text { troops } \\
7 \text { troops }\end{array}$ & $\begin{array}{l}4 \\
4\end{array}$ & $\begin{array}{l}0.077 \\
0.062\end{array}$ & $\begin{array}{l}- \\
-\end{array}$ & $\begin{array}{l}\text { Dracopoli et cl. } 1983 \\
\text { Turner } 1981\end{array}$ \\
\hline Homo sapiens & & & & & \\
\hline $\begin{array}{l}\text { Yanomama } \\
\text { Makiritare }\end{array}$ & $\begin{array}{l}37 \text { villages } \\
7 \text { villages }\end{array}$ & $\begin{array}{l}11 \\
13\end{array}$ & $\begin{array}{l}0.063 \\
0.036\end{array}$ & $\begin{array}{l}-0.008 \\
-0.007\end{array}$ & Neel and Ward 1972 \\
\hline
\end{tabular}

and inferred inbreeding in the stable population, there was a significant excess of heterozyosity within troops in both populations. The observed genetc differentiation among troops was promoted by a single-male harem breeding sructure, a very low rate of random exchange of breeding males among troops, and a high degree of relatedness among troop females. In contrast, Scheffrahn and de Ruiter's (1994) study of long-tailed macaques Macaca fascicularis with similır social structure, shows genetic differentiation to be slightly less than $5 \%$ with a mean positive $F_{I S}$ for seven adjacent social groups. In this latter case breeding is shared between the $\alpha$-male $(80 \%)$ and $\beta$-male $(20 \%)$, with a tendency for the $\beta$-male to increase his share in low-ranking matrilines.

Data for three species of bats with contrasting social structures indicate that genetic structuring may occur among social groups of adults as a result $o^{3}$ kinship 
(Wilkinson 1985) or among groups of juveniles as a result of polygamy and genetic drift (McCracken and Bradbury 1981). Phyllostomus hastatus has a highly polygynous breeding system in which a single male defends harems containing an average of 18 adult females (McCracken 1987). Were he to father all offspring in the harem, effective population size would be reduced to approximately $35 \%$ of that under monogamous mating and one might predict significant genetic differentiation among harem groups. McCracken and Bradbury (1981) found no significant genetic heterogeneity among nine harems investigated. In this species all offspring disperse, with males joining bachelor groups and females born in different harems and cave colonies assembling to form stable, new harems. Estimates of average relatedness within harems are low $(0.037$; Wilkinson and McCracken 1985), and it appears that juvenile dispersal negates any effect harem polygyny might have on genetic structure. In contrast, female natal philopatry in Desmodus rotundus results in genetic differentiation of almost $8 \%$ among groups of females (Wilkinson 1985). Relatedness is low within groups $(<0,1)$, due to multiple matrilines in a group, and the fact that relatedness is only through the female lineage. Males disperse and their mating success is correlated with roosting position, although most males succeed in mating. In Saccopteryx bilineata where roost site fidelity of adult males is high, genetic data indicate that the male populace may be weakly structured. In contrast females move frequently among harems and colonies and there is no evidence for structuring among female groups.

Chesser (1983) explored partitioning of genetic variance in the black-tailed prairie dog Cynomys ludovicianus, one of the most socially complex vertebrates where breeding groups (coteries) comprise a single male and 2-8 mature females. He found significant differentiation among coteries within wards (Table 2), and interpreted the postive $F_{I S}$ as indicating relatively high levels of inbreeding, though inflated also by a Wahlund effect. Significant potential for error in the method used for designating coterie membership may also be implicated. Foltz and Hoogland (1983) adopted a pedigree approach, gathering seven years of data on a single population of praire dog. They consider these data barely adequate to detect consanguinity, and that inbreeding coefficients simply reflect increasing depth in the pedigree. They observed negative $F_{I S}$ values for offspring and conclude that avoidance of consanguineous matings, selection and sex related allele frequency differences are responsible. On the basis of high observed heterozygosity, moderate heterogeneity between widely separated colonies, and the high rate of migration observed among colonies, Foltz and Hoogland (1983) suggested that black-tailed prairie dogs are relatively outbred.

Van Staaden et al. (1994) detected significant genetic differentiation among nine matrilines of Richardson's ground squirrels $S$. richardsonii. Correlation of genetic distance and coancestry matrices, based on six loci and matrilineal pedigrees from seven generations respectively, indicated that neighboring females tended to be more related than would be expected due to chance not only within the entire population, but within individual matrilines as well. For combined 
matrilines, the matrices of genetic distance and coancestry were significantly negatively correlated; but for individual matrilines the relationship was variable, indicating that the predictability of kinship from genotypic data alone is unreliable at this fine scale and relatively low level of genetic variability. While female philopatry clearly gives rise to non-random spatial and genetic associations of related individuals, it is somewhat surprising to find significant differentiation in what is generally considered to be a sciurid species with a relatively low level of social complexity. Van Staaden et al. (1994) propose that the female dispersion pattern moderates random male mating during an explosive breeding period, resulting in genetically distinct groups of females characterized by low levels of genetic variance.

\section{Interpretations and limitations}

The previous review suggests a diversity of opinions regarding the existence of genetic structuring in mammalian populations. Several studies have concluded that while spatial heterogeneity in genotypic distributions may result from sociality, this heterogeneity does not result in locally inbred, genetically structured populations (Schwartz and Armitage 1980, Patton and Feder 1981, McCracken 1987). In others the case for significant structure, in species ranging from mice to humans, is clearer and we can relate the observed genetic patterns to specific behaviors, albeit post hoc (van Staaden et al. 1994). The primary reason for this dissent appears to be largely interpretive rather than statistical.

Although we do not yet know what degree of differentiation may be biologically rather than simply statistically significant, requirements of structure implicit in several studies are highly variable. Whereas some consider the identification of statistically significant, non-random patterning of genetic markers to be sufficient, others regard the demonstration of biological or evolutionary significance a necessary prerequisite (McCracken and Bradbury 1977, Bowen 1982, Melnick 1982). For yet others the existence of kinship within groups (McCracken 1987), exchange between groups (Daly 1981), or low predictability of form and relatively high turnover rate (Myers 1974) preclude the existence of genetic structure. The small size of many mammalian social groups means that there is necessarily a high degree of stochasticity in genetic parameters, and a susceptiblity to statistical sampling effects. It is parsimonious to admit that while this certainly complicates the identification of genetic structure it is not an insurmountable problem. Moreover, this stochastic variation is precisely what natural selection is acting on. What we are most interested in then, is that subset of populations exhibiting statistically significant genetic structure closely related with social structure.

The type of genetic data (ie alleles or genotypes) used to investigate structure varies between studies, and is a central cause of confusion. We need clearly to distinguish between structure resulting from some relatively long term and distinct separation of subgroups in the population (genetic structure sensu stricto), 
and the underlying breeding structure resulting from transient variations in mating tactics. Empirically this may be achieved by analysing the structure of genotypes versus alleles (Chesser and Van Den Bussche 1988), or by analysing parent and offspring generations separately (Spielman et al. 1977). Conflation of adult and offspring samples will usually dilute the magnitude of fixation indices and obscure the underlying breeding structure (see Long 1986), but this is not always so (Table 1). In a population of Richardson's ground squirrels conflating groups dilutes the $F_{S T}$ for mothers and their recruited offspring, but enhances it in the case of pregnant females and their embryos. The greater differentiation between embryos than between pregnant females indicates that mating within matrilines was not independent.

Concluding a lack of genetic structure frequently seems to derive from the assumption that social groups of mammals should be inbred (eg Schwartz and Armitage 1980, McCracken 1987). These instances parallel the misinter- pretation of $F$-statistics at the level of the single population, when extrapolated from those for geographically separated populations; for example when $F_{I S}$ is used as a measure of individual inbreeding and $F_{I S}$ values indicating excess heterozygosity within lineages are interpreted as evidence of inbreeding avoidance (Schwartz and Armitage 1980, Foltz and Hoogland 1983). Since the tendency to negative $F_{I S}$ now has a firm statistical footing, and it has been shown that breeding structure alone can result in negative $F_{I S}$ values (Chesser 1991b), the suggestion that this may constitute a mechanism for retarding random fixation among social groups (Neel and Ward 1972) should be entertained.

Turning now to practical problems, it is clear that those who have presented evidence that genetic structure results from sociality (Selander 1970, Chesser 1983), nonetheless recognize the difficulties of interpreting true causes of inbreeding estimates derived solely from field data of genotype estimates (O'Brien 1987, van Staaden et al. 1994). To date the most commonly used genetic markers have been allozymes, although Amos et al. (1993) recently used microsatellites for the analysis of population structure in whales. Allozymes may not provide sufficient resolution for the detection of fine-scale genetic structure in many mammals, particularly as social species tend to have low variability within groups. Moreover, selection compounds the detection problem (Epperson 1990) and hampers interpretations with respect to social structure (see Daly 1981, Foltz and Hoogland 1983). The study site in the former was fully enclosed, encompassing two distinct habitats defined by soil type with clear differences in resource availability. In the latter, fixation indices differed significantly across loci but were homogeneous across years, suggesting that the observed heterozygote excess might be caused by selective differences among genotypes.

Although the small size of the geographic area under study has been cited as a reason for failure to detect structure (White and Svendsen 1992), it is likely that sampling regimes are more consequential. Where less than $50 \%$ of a population is assayed the probability of detecting significant structure is much reduced. 
Moreover, whether comparing empirical data with other populations (White and Svendsen 1992) or with simulations (Waser and Elliott 1991), sampling conditions should be equitable. White and Svendsen (1992) sampled less than $50 \%$ of resident chipmunk over a maximum separation distance of $280 \mathrm{~m}$, and contrast the lack of structure with that determined in a much larger sample along a $3 \mathrm{~km}$ transect, equivalent to 54-84 times the estimated dispersal distance of males and females repectively, and several hundred times across a typical home range. Similarly, it is difficult to make comparisons between a small study population and simulations in which a single patch is several times larger (Epperson 1993).

Epperson (1993) has provided an excellent review of recent advances in autocorrelation studies and extensively discussed the relative advantages and disadvantages of this technique for detection of population structure. Whereas its use for exploratory data analysis and testing the statistical significance of correlations is unquestioned, its utility for drawing inferences about processes is arguable (Slatkin and Arter 1991, Sokal and Oden 1991). There are two main problems; firstly, the inherently stochastic character of population genetic mechanisms, and secondly, that there appears to be no general way to deduce the form of the spatial autocorrelogram expected for a given set of assumptions about behavior. However, in computer simulations, the $\mathrm{x}$-intercept consistently reflects parameter values of neighborhood size and mating system (Sokal and Wartenburg 1983), and statistics for join counts between like-homozygotes do measure patch size in both simulated (Epperson 1990) and real (Epperson and Clegg 1986) populations. Although in practise, spatial autocorrelation has often been used to analyze patterns of allele frequency it has rarely been employed to analyze the distribution of individual genotypes within a local population (Epperson 1990). Moreover, few empirical studies fulfil the sampling requirements necessary to detect structure, ie a nearly uniform sample lattice physically covering an area expected to contain at least 4-9 patches, with at least 10-20 sample points for each patch area (Epperson 1993). Although social (and therefore genetic) structure is not necessarily reflected spatially, mammals such as fossorial rodents which are geographically restricted, are the easiest systems to assay. Nonetheless, most empirical studies employing spatial autocorrelation have still failed to detect structure. To some extent this may be because they fail to take behavioral variation into account, eg sex differences, and difference between residence and breeding locations (see Waser and Elliott 1991, White and Svendsen 1992). For these reasons, the performance of spatial autocorrelation in detecting genetic structure in mammalian populations has been disappointing.

If stochastic variance is sufficiently large, then detecting structure on the basis of genetic data alone is extremely difficult (perhaps impossible) on a fine scale, and no statistical method can be expected to overcome the noise generated. A behavioral approach may be more robust. Behavioral factors affecting population genetic structure include unequal variances in reproductive success between the sexes, the phenomenon of lineal fissioning, and social organization in restricting 
gene flow. When behavior or a priori kinship coefficients were used to identify social groups, studies have met with most success (Pope 1992, van Staaden et al. 1994), and deviations from expected values of fixation indices provide a convenient estimate of population divergence and indications of nonrandom mating within the population.

Such analyses using several types of data from a single population may provide a better understanding of the way in which breeding tactics and social structure affect genetic structure than analysis of any one form of data. However, behavior is the most complex of phenotypes and the success of this approach hinges on an authentic definition of the social sy:tem and the accurate delineation of breeding groups. Social structure is not a system of unique, discrete levels, and the difficulties of defining subgroups reaches an extreme in fission-fusion societies which have social organization characterized by flexibility in size and composition of groups within a community (eg lion, porpoises and various monkeys; Chapman et al. 1993). Behavioral plasticity occurs at the species, population (Apollonio and Hartl 1993), social group, and individual levels. For example, the Nilgiri langur Presbytis johnii has a social system highly variable between troops, apparently dependant on idiosyncratic behavioral traits of individuals (Poirer 1969). Such behavioral flexibility of mammals has important consequences because context-specific behavior limits the generality of any possible rules (Dunbar 1988).

I have reviewed studies of genetic structure and find that where known social groups are compared, significant structure seems to be the rule. Many of the contrary claims in the literature appear to be unjustified, primarily because of technical limitations. Until data are available from populations in which both social and genetic interactions are equally well known, it is premature to conclude that genetic structure is absent in natural populations of mammals, and that social level and genetic structure are not closely correlated (Lidicker and Patton 1987).

In the above discussion I have treated the concept of population genetic structure as a necessary outcome of certain social structures and breeding tactics; whether genetic structure also plays a role in initiating the evolution of expensive social behaviors is less clear. Michod and Sanderson (1985) maintain that the necessity of genetic structure for the evolution of expensive social behaviors stems from simplifying assumptions made concerning the relationship of genotype and behavior. In models which assume all differences in behavior are caused by differences in genotype (kin selection, assortment of encounters, group selection), genetic structure is vital to generate behavioral structure. On the contrary, Michod and Sanderson (1985) propose that where behaviorally flexible individuals choose behaviors according to some rule (reciprocation models), behavioral structure is generated by the learning process and genetic structure is no longer necessary for costly behaviors to evolve. If so, this might be one reason why empirically observed structure is not as rigid as some anticipate, and we would predict that, all else being equal, genetic structure will be strongest in social species with relatively closed behavioral programs. 


\section{Future prospects}

The demonstration of a consistent negative $F_{I S}$ relationship in studies with identifed social groups, or clustering of rare alleles (Epperson 1993), would constitute compelling evidence of structure. Social models of population genetic structure (Chesser 1991a, b, Nunney 1993) provide an interpretive framework and promote the generation of testable hypotheses rather than simple description. Empirical goals include comparisons of structure in multiple populations to assess the degree of stochasticity in form and scale of genetic structure within species. Repeated assays of spatial distribution of identified individuals will serve to determine the temporal stability of genetic structure. Separate analyses of fixation indices for breeding adults and offspring are needed to explore breeding structure independently of genetic structure. To test the proposition that social level and genetic structure are not closely correlated (Lidicker and Patton 1987), we require data from closely related taxa with divergent social structures. Occurrences of intraspecific variation in breeding tactics and social structure may be exploited to similar effect. Finally, experimental studies in which populations are manipulated (eg by chemical control of fertility to increase variance in reproductive success, or by perturbation of social groups), will provide more direct evidence of the relative importance of breeding and social behaviors for genetic structure.

At present the only unequivocal method for determining population structure is demographic and behavioral data (eg pedigrees, genetically effective migration), combined with surveys of gene frequencies and differentiation. Codominant, selectively neutral, and highly polymorphic genetic markers are required for the resolution of fine-scale genetic structure. Several recent innovations in molecular genetics are applicable. Improved estimates of genetic variability may be obtained from DNA sequencing, or from random amplified polymorphic DNA which has appealing properties and may be used with some caveats (Ellsworth et $\mathrm{cl}$. 1993); microsatellites will be particularly useful since the advent of comnercially available primers permit anonymous screening.

Powerful analytical methods such as $F$-statistic analogues applicable to DNA sequence and restriction-map data (Lynch and Crease 1990) need to be applied to multiple 'loci' to determine the distribution of genetic variability within ard among identified social groups. Supplemental use of Mantel matrix correlations (Mantel 1967, Douglas and Endler 1982), spatial autocorrelation (Epperson 1993), and contiguous clustering methods (Chesser and Van Den Bussche 1988) will enable us to construct expectations for given social/breeding systems and assess tie future utility of these methods for analysing genetic structure in mammalian populations. Studies of genetic structure which use a simultaneous integration of both ethological and population genetic approaches will be invariably stronger than single tests, and will begin to provide the information that will eventualy lead to a synthesis of the disparate models. 
Acknowledgements: Support for this work was provided by the Senate Committee of International Relations of Karl-Franzens-Universität Graz and the Fonds zur Förderung der wissenschaftlichen Forschung (project P09523-Bio to H. Römer). I thank G. Gerlach, R. Huber and D. McCullough for comments on the manuscript, and M. Baldellou and B.-A. Gereben for their assistance.

\section{References}

Amos B., Schöltterer C. and Tautz D. 1993. Social structuring of pilot whales revealed by analytical DNA profiling. Science 260: 670-672,

Apollonio M. and Hartl G. B. 1993. Are biochemical-genetic variation and mating systems related in large mammals? [In: Ecological genetics in mammals. G. B. Hartl and J. Markowski, eds]. Acta Theriologica 38, Suppl. 2: 175-186.

Baker M. C. and Marler P. 1980. Behavioral adaptations that constrain the gene pool in vertebrates. [In: Evolution of social behavior: hypotheses and empirical tests. H. Markl, ed]. Verlag Chemie, Weinheim: 59-80.

Bowen B. S. 1982. Temporal dynamics of microgeographic structure of genetic variation in Microtus californicus. Journal of Mammalogy 63: 625-638.

Chapman C. A., White F. J. and Wrangham R. W. 1993. Defining subgroup size in fission-fusion societies. Folia Primatologica 61: 31-34.

Chepko-Sade B. D. and Shields W. M. 1987. The effects of dispersal and social structure on effective population size. [In: Mammalian dispersal patterns: the effects of social structure on population genetics. B. D. Chepko-Sade and Z. T. Halpin, eds]. University of Chicago Press, Chicago: $287-321$.

Chesser R. K. 1983. Genetic variability within and among populations of the black-tailed prairie dog. Evolution 37: 320-331.

Chesser R. K. 1991a. Gene diversity and female philopatry. Genetics 127: 437-447.

Chesser R. K. 1991b. Influence of gene flow and breeding tactics on gene diversity within populations Genetics 129: 573-583.

Chesser R. K., Sugg D. W., Rhodes O. E., Jr, Novak J. N. and Smith M. H. 1993. Evolution of mammalian social structure. [In: Ecological genetics in mammals. G. B. Hartl and J. Markowski, eds1. Acta Theriologica 38, Suppl. 2: 163-174.

Chesser R. K. and Van Den Bussche R. A. 1988. Contiguous clustering: a method for the identification of clusters within populations. Occasional Papers of the Museum, Texas Tech University 122: $1-13$.

Daly J. C. 1981. Effects of social organization and environmental diversity on determining the genetic structure of a population of the wild rabbit Oryctolagus cuniculus. Evolution 35: 689-706.

De Fries J. C. and McClearn G. E. 1972. Behavioral genetics and the fine structure of mouse populations: a study in microevolution. [In: Evolutionary biology Vol. 5. T. Dobzhansky, M. K. Hecht and W. C. Steere, eds]. Appleton-Century-Crofts, New York: 279-291.

Douglas M. E. and Endler J. A. 1982. Quantitative matrix comparisons in ecological and evolutionary investigations. Journal of Theoretical Biology 99: 777-795.

Dracopoli N. C., Brett F. L., Turner T. R. and Jolly C. J. 1983. Patterns of genetic variability in the serum proteins of the Kenyan vervet monkey (Cercopithecus aethiops). American Journal of Physical Anthropology 61: 39-49.

Dunbar R. I. M. 1988. The evolutionary implications of social behavior. [In: The role of behavior in evolution. H. C. Plotkin, ed]. MIT Press, Cambridge MA: 165-188.

Ellsworth D. L., Rittenhouse K. D. and Honeycutt R. L. 1993. Artifactual variation in randomly amplified polymorphic DNA banding patterns. Biofeedback 14: 214-216. 
Epperson B. K. 1990. Spatial autocorrelation of genotypes under directional selection. Genetics 124: $757-771$.

Epperson B. K. 1993. Recent advances in correlation studies of spatial patterns of genetic variation. [In: Evolutionary biology Vol. 27. M. K. Hecht, B. Wallace and R. J. MacIntyre, eds]. Plenum Press, New York: 95-151.

Epperson B. K. and Clegg M. T. 1986. Spatial autocorrelation analysis of flower color polymorphisms within substructured populations of morning glory (Ipomoea purpurea). American Naturalist 128: $840-858$.

Foltz D. W. and Hoogland J. L. 1983. Genetic avoidance of outbreeding in the black-tailed prairie dog (Cynomys ludovicianus). Evolution 37: 273-281.

Gaines M. S. and Krebs C. J. 1971. Genetic changes in fluctuating vole populations. Evolution 25: $702-723$.

Jong G., de, de Ruiter J. R. and Haring R. 1994. Genetic structure of a population with social structure and migration. [In: Conservation genetics. V. Loeschcke, J. Tomiuk and S. K. Jain, eds]. Birkhauser Verlag, Basel: 147-164.

Lidicker W. Z. and Patton J. L. 1987. Patterns of dispersal and genetic structure in populations of small rodents. IIn: Mammalian dispersal patterns: the effects of social structure on population genetics. B. D. Chepko-Sade and Z. T. Halpin, eds]. University of Chicago Press, Chicago: 144-161.

Long J. C. 1986. The allelic correlation structure of Gainj- and Kalam-speaking people. I. The estimation and interpretations of Wright's $F$-statistics. Genetics 112: 629-647.

Lynch M. 1991. Analysis of population genetic structure by DNA fingerprinting. Experientia 58: 113-126.

Lynch M. and Crease T. J. 1990. The analysis of population survey data on DNA sequence variation. Molecular Biology and Evolution 7: 377-394.

Lynch M. and Milligan B. G. 1994. Analysis of population genetic structure with RAPD markers. Molecular Ecology 3: 91-99.

Mantel N. 1967. The detection of disease clustering and a generalized regression approach. Cancer Research 27: 209-220.

Mayr E. 1965. Animal species and evolution. Harvard University Press, Cambridge: 1-797.

McCracken G. F. 1987. Genetic structure of bat social groups. [In: Recent advances in the study of bats. M. Brock Fenton, P. Racey and J. M. V. Rayner, eds]. Cambridge University Press, Cambridge: 281-298.

McCracken G. F. and Bradbury J. W. 1977. Paternity and genetic heterogeneity in the polygynous bat Phyllostomus hastatus. Science 198: 303-306.

McCracken G. F. and Bradbury J. W. 1981. Social organization and kinship in the polygynous bat, Phyllostomus hastatus. Behavioral Ecology and Sociobiology 8: 11-34.

Melnick D. J. 1982. Are social mammals really inbred? Genetics 100: 146.

Melnick D. J., Jolly C. J. and Kidd K. K. 1984. The genetics of a wild population of rhesus monkeys (Macaca mulatta). I. Genetic variability within and between social groups. American Journal of Physical Anthropology 63: 341-360.

Michod R. E. and Sanderson M. J. 1985. Behavioural structure and the evolution of cooperation. [In: Evolution: Essays in honour of John Maynard Smith. J. J. Greenwood and M. Slatkin, eds]. Cambridge University Press, Cambridge: 95-104.

Myers J. H. 1974. Genetic and social structure of feral house mouse populations on Grizzly Island, California. Ecology 55: 747-759.

Neel J. V. and Ward R. H. 1972. The genetic structure of a tribal population, the Yonomama Indians. VI. Analysis by $F$-statistics (including a comparison with the Makiritare and Xavante). Genetics 72: 639-666.

Nunney L. 1993. The influence of mating system and overlapping generations on effective population size. Evolution 47: 1329-1341. 
O'Brien E. 1987. The correlation between population structure and genetic structure in the Hutterite population. [In: Mammalian dispersal patterns: the effects of social structure on population genetics. B. D. Chepko-Sade and Z. T. Halpin, eds]. University of Chicago Press, Chicago: $193-210$.

Patton J. L. and Feder J. H. 1981. Microspatial genetic heterogeneity in pocket gophers: non-random breeding and drift. Evolution 35: 912-920.

Petras M. L. 1967. Studies of natural populations of Mus I. Biochemical polymorphisms and their bearing on breeding structure. Evolution 21: 259-274.

Plomin R. 1990. The role of inheritance in behavior. Science 238: 183-188.

Poirer F. E. 1969. Behavioral flexibility and intergroup variation among Nilgiri langurs (Presbytis johnii) of South India. Folia Primatologica 11: 119-133.

Pope T. J. 1992. The influence of dispersal patterns and mating system on genetic differentiation within and between populations of the red howler monkey (Alouatta seniculus). Evolution 46: $1112-1120$

Scheffrahn W. and de Ruiter J. R. 1994. Genetic relatedness between populations of Macaca fascicularis on Sumatra. [In: Evolution and ecology of macaque societies. J. E. Fa and D. G. Lindburg, eds]. Cambridge University Press, Cambridge. (in press)

Schwartz O. A. and Armitage K. B. 1980. Genetic variation in social mammals: the marmot model. Science 207: 665-667.

Selander R. K. 1970. Behavior and genetic variation in natural populations. American Zoologist 10: 53-66.

Singleton G. R. 1983. The social and genetic structure of a natural colony of house mice Mus musculus at Healesville Wildlife Sanctuary, Australia. Australian Journal of Zoology 31: 155-166.

Slatkin M. and Arter H. E. 1991. Spatial autocorrelation methods in population genetics. American Naturalist 138: 499-517.

Sokal R. R. and Oden N. L. 1991. Spatial autocorrelation analysis as an inferential tool in population genetics. American Naturalist 138: 518-521.

Sokal R, R. and Wartenburg D. E. 1983, A test of spatial autocorrelation analysis using an isolation-by-distance model. Genetics 105: 219-237.

Spielman R. S., Neel J. V. and Li F. H. F. 1977. Inbreeding estimation from population data: models, procedures and implications. Genetics 85: 355-371.

Templeton A. R. 1987. Inferences on natural population structure from genetic studies on captive mammalian populations. [In: Mammalian dispersal patterns: the effects of social structure on population genetics. B. D. Chepko-Sade and Z. T. Halpin, eds]. University of Chicago Press, Chicago: 257-272.

Turner T. R. 1981. Blood protein variation in a population of Ethiopian vervet monkeys (Cercopithecus aethiops aethiops). American Journal of Physical Anthropology 55: 225-232.

van Staaden M. J., Chesser R. K. and Michener G. R. 1994. Genetic correlations and matrilineal structure in a population of Spermophilus richardsonii. Journal of Mammalogy 75: 573-582.

van Staaden M. J., Michener G. R. and Chesser R. K. Spatial analysis of microgeographic genetic structure in Richardson's ground squirrels. (submitted)

Waser P. M. and Elliott L. F. 1991. Dispersal and genetic structure in kangaroo rats. Evolution 45: 935-943.

White M. M. and Svendsen G. E. 1992. Spatial-genetic structure in the eastern chipmunk, Tamias striatus. Journal of Mammalogy 73: 619-624.

Wilkinson G. S. 1985. The social organization of the common vampire bat. II. Mating system, genetic structure and relatedness. Behavioral Ecology and Sociobiology 17: 123-134.

Wilkinson G. S. and McCracken G. F. 1985. On estimating relatedness using genetic markers. Evolution 39: 1169-1174. 
Wilson A. C., Bush G. L., Case S. M. and King M.-C. 1975. Social structuring of mammalian populations and rate of chromosomal evolution. Proceedings of National Academy of Science 72: 5061-5065.

Wright S. 1943. Isolation by distance. Genetics 28: 114-118.

Wright S. 1951. The genetical structure of populations. Annals of Eugenics 15: 323-354.

Received 20 March 1995, accepted 30 August 1995. 